\title{
O OPEN ACCESS E AS COMUNIDADES ACADÊMICAS DA ÁREA DE BIBLIOTECONOMIA NO NORDESTE DO BRASIL
}

\author{
Virgínia Bárbara de Aguiar Alves \\ Doutora em Ciência da Informação \\ Professora Adjunta do Curso de Biblioteconomia \\ Universidade Federal de Alagoas \\ virginiabarbara@ua.pt
}

\begin{abstract}
Resumo
Verificar a influência do Open Access (OA), nas comunidades acadêmicas da área de biblioteconomia das Universidades Federais da Região Nordeste do Brasil. Tem como objetivo geral identificar e discutir a influência do movimento OA. A metodologia adotada consiste na combinação da abordagem qualitativa e quantitativa; os instrumentos de recolha de dados utilizados foram questionários e entrevista. A entrevista foi aplicada ao tecnólogo sênior do Instituto Brasileiro de Informação, Ciência e Tecnologia (IBICT), com a finalidade de obter informações sobre o movimento OA no Brasil. Os questionários foram aplicados aos professores e alunos dos cursos de Biblioteconomia, com a finalidade de verificar os efeitos e as consequências do movimento $\mathrm{OA}$ sobre essas comunidades. Os resultados dos inquéritos apontam vários indicadores positivos da influência do movimento OA sobre essas comunidades acadêmicas, entre os quais podemos citar: a existência de repositórios institucionais em Universidades Federais Nordestinas, um alto percentual de utilização de repositórios institucionais, o elevado percentual de utilização e produção de publicações bibliográficas em OA; o conhecimento e a concordância com o movimento OA demonstram o impacto desse movimento nas comunidades acadêmicas da Região Nordeste do Brasil.
\end{abstract}

Palavras-chave

Acesso livre. Acesso livre - influência. Acesso livre - Região Nordeste do Brasil.

\section{INTRODUÇÃO}

A procura da informação e a sua disseminação atravessaram gerações e, entre o final do século XX e o início do século XXI, surgiu o movimento do Open Access $(\mathrm{OA})$, um modelo alternativo para a comunicação científica, que vem contribuindo para a consolidação desse sonho. O modelo estabeleceu padrões para a interoperabilidade entre bibliotecas digitais e repositórios temáticos e institucionais, desencadeando uma verdadeira rede de eventos, com o objetivo de apoiar o movimento para o acesso aberto ao conhecimento científico.

Exemplos do impacto do modelo implementado são: a Declaração Sobre a Ciência no Século XXI (1999) e a Budapest Open Access Initiative (2002); a reunião promovida pelo Open Society Institute (OSI), a qual estabeleceu duas estratégias - a via verde (auto-arquivamento em repositórios institucionais e temáticos) e a via dourada (publicação em revistas de acesso livre); a Bethesda Statement on Open Access Publishing (2003), visando estabelecer princípios para obter apoio formal das agências de 
financiamento e de todos os atores do fluxo da comunicação científica para a publicação de resultados de pesquisa científica; a Berlin Declaration on Open Access to Knowledge in Sciencies \& Humanities (2003), que recomenda o uso consistente da Internet para divulgação e publicação das pesquisas científicas, encorajando os pesquisadores a publicarem os seus trabalhos em revistas de acesso livre, além de endossar as declarações anteriores; a International Federation of Library Associations and Institutions (IFLA) on Open Access for Scholarly Literature (2003), que afirma que abrir o acesso à literatura científica e a resultados de pesquisa é fundamental para compreensão do mundo e para identificação de solução aos desafios globais, e, em particular, a redução da desigualdade de informação; a Declaração de Salvador para Acesso Aberto (2005), que conclama a todos os parceiros da comunidade científica internacional para, conjuntamente, assegurar que a informação científica seja de livre acesso e disponível para todos; o Manifesto Brasileiro Sobre Acesso Livre - Brasil (2005), que chama a comunidade científica brasileira a apoiar o movimento mundial em favor do acesso livre à informação científica.

A pesquisa que apresentamos se insere na área da Ciência da Informação, e a temática compreende questões relativas à comunicação científica e, de uma forma específica, ao Movimento do Acesso Livre. $\mathrm{O}$ estudo pretende, concomitantemente, identificar e discutir a influência do movimento OA nas comunidades acadêmicas da área de Biblioteconomia nas Universidades Federais da Região Nordeste do Brasil. Nesse sentido, a metodologia empregue na construção desta investigação envolve: a recolha de dados, nomeadamente, através de entrevistas e questionários, com pessoas que têm experiências e práticas com as questões relativas à produção, à disseminação e ao uso da informação científica, fazendo, neste contexto, a análise de exemplos que estimulem a compreensão do tema.

Tem como objetivo geral identificar e discutir a influência do movimento OA nas comunidades acadêmicas da área de
Biblioteconomia das Universidades Federais da Região Nordeste do Brasil, nomeadamente nas Universidades Federais da Bahia, Alagoas, Pernambuco, Paraíba, Ceará, Rio Grande do Norte e do Maranhão, com ênfase sobre as questões relativas à "via verde" e à "via dourada". As duas vias, enquanto estratégias básicas do Movimento do OA, foram estabelecidas com a finalidade de acelerar a disseminação do conhecimento científico. Como objetivos específicos, a investigação pretendeu: estabelecer um paralelo entre as duas estratégicas básicas, definidas em Budapeste, sendo a primeira estratégia o autoarquivamento, que constitui a via verde (Green Road) e a segunda estratégia, os periódicos eletrônicos de acesso aberto, que constituem a via dourada (Golden Road); verificar a importância da utilização das vias verde e dourada para a disseminação da informação, como uma alternativa aos mecanismos tradicionais de comunicação científica no meio acadêmico; relacionar a diferença entre legitimação e legitimidade das publicações eletrônicas de acesso aberto, com o uso da via verde e da via dourada; discutir a importância da Open Archives Initiative (OAI) na implementação do movimento do OA.

Como questão de investigação apresentamos: quais os efeitos/consequências que a via verde e a via dourada de disseminação da informação trazem para a comunicação científica? Como hipótese, a afirmação abaixo descrita: o Movimento do OA, que utiliza as via verde e dourada, como estratégias de ação na disseminação da informação, proporciona um novo modelo, mais vantajoso para comunicação científica nas comunidades acadêmicas, localizadas na Região Nordeste do Brasil.

O movimento do acesso livre vem procurando tornar possível a comunicação científica entre milhares de pesquisadores espalhados pelo mundo, quebrando, assim, as barreiras geográficas e facilitando a disseminação da literatura científica, constituindo-se como meio essencial para a construção do conhecimento, que compreende a produção, a comunicação 
(disseminação do conhecimento) e a aplicação do conhecimento gerado na criação de novos conceitos.

\section{DISCUSSÃO}

De acordo com Carvalho e Kaniski (2000 apud BINOTTO, 2007), a história da ciência vem se modificando, configurando períodos de normalidade e períodos de revolução, com a invenção da escrita e da imprensa: a escrita possibilitou a preservação dos registros do conhecimento, o que proporcionou a difusão cultural, e a imprensa tornou possível o acesso a esse mesmo conhecimento em uma área obsoleta e separada de outros debates, onde manifestam tendências de democratização e universalização da cultura geral e científica.

A introdução de novas tecnologias de informação, com suas possibilidades de interatividade, hipertextualidade (liberdade na criação de textos provendo interconexões entre informações vinculadas) e hipermediação, provocou uma mudança rápida do ambiente e no aumento de publicações eletrônicas. $\mathrm{O}$ atual desenvolvimento de tecnologias de informação e da Rede Internet gerou mudanças nos conceitos de canais formais e informais de comunicação e introduziu inovações no que diz respeito à interação no processo de construção do conhecimento científico (MORENO; ARELLANO, 2005).

Com a Internet e, muito particularmente, a World Wide Web, houve uma mudança de paradigma do modelo tradicional de comunicação, facilitando a troca de informação entre pesquisadores. A rede passa a ser um instrumento de comunicação de fácil acesso que possibilita a rapidez e a visibilidade no intercâmbio de informações (SENA, 2006, p. 72). A rapidez alcançada na disseminação de informações gerou um contraste entre a produção e a distribuição de revistas científicas impressas com a agilidade das publicações eletrônicas.

Num período "anterior ao surgimento da Rede, toda a publicação científica era produzida em papel a um custo alto. Ainda hoje, devido a fatores econômicos ou por problemas de distribuição, os pesquisadores enfrentam sérias dificuldades de acessar grande parcela da literatura científica" (CAFÉ; LAGE, 2002).

As editoras comerciais criam barreiras para a obtenção de informação e para a sua divulgação. Os altos custos das publicações científicas, em formato impresso e também em formato eletrônico, são obstáculos para vários pesquisadores, bibliotecas e instituições de ensino e pesquisa, mesmo as instituições que possuem grandes recursos não têm como acessar todas as publicações científicas.

Tradicionalmente, o principal veículo de divulgação dos resultados de pesquisas em ciência e tecnologia é o periódico científico. $\mathrm{O}$ artigo científico se torna o elemento indicador primeiro da produção científica, integrando $\mathrm{O}$ sistema de reconhecimento científico (Cronin e Overfelt, 1995), concedendo visibilidade, contribuindo para a promoção da carreira acadêmica e científica e facilitando a obtenção de financiamentos junto a órgãos de fomento a pesquisa (MEADOWS, 1999; ZIMAN, 1979 apud FERREIRA; MUNIZ, [2005]).

A crise no setor dos periódicos, de acordo com Moraes (2006, p. 25), foi marcada por fatores, como: a) a fusão das editoras comerciais; b) o aumento dos preços das revistas, que em pouco tempo abalou a continuidade das assinaturas e, por isso, muitas bibliotecas excluíram vários títulos; c) as vendas de assinaturas por pacotes em que os custos diminuíam e neles eram incluídas revistas que não interessavam às bibliotecas, sendo que também passavam a ter títulos que antes não podiam pagar; d) consórcios de bibliotecas para auxiliar a 
negociação com as grandes editoras, as bibliotecas se agregaram em consórcio para comprar material científico e disponibilizá-lo ao usuário através de intercâmbio ou pela Comutação Bibliográfica (COMUT). Toda essa situação foi agravada pela inexistência de concorrência, o que monopolizou o mercado deixando as instituições sem opção, porque a "ciência não existe sem comunicação" (MORAES, 2006, p. 25).

De acordo com Soares (2004, p. 13), o aumento dos custos das revistas acima do índice geral de preços não é recente, e os bibliotecários foram os primeiros a enfrentar esse problema, juntamente com os administradores universitários. Os pesquisadores só tiveram conhecimento do problema quando lhes solicitado suprimirem algumas assinaturas. $\mathrm{O}$ aumento dos custos intensificou-se nas últimas décadas e estes inviabilizaram os orçamento das universidades e institutos de pesquisas, abalando o funcionamento das universidades americanas, especialmente as que tinham menos recursos. Ainda de Acordo com o autor supracitado (2004, p. 15), o resultado foi desastroso mesmo para grandes universidades com reconhecido valor e, inclusive, algumas bibliotecas decidiram cancelar mais de 500 assinaturas de revistas.

De acordo com Sena (2006, p. 72), torna-se evidente a discrepância entre a morosidade do processo da comunicação científica tradicional e a rapidez com que algumas áreas do conhecimento se desenvolvem e promovem a divulgação dos seus trabalhos. Nesse contexto, surge a questão da transferência dos direitos autorais para os editores, o que nem sempre atende aos interesses dos autores. Além disso, a importância do processo de revisão feita pelos autores e o tempo despendido limitam o processo de disseminação de novas ideias, facilitando a promoção de grupos restritos de editores e autores. Segundo Jacobs (2006, p. 1), as preocupações relativas ao tenso sistema de comunicação acadêmica levaram à proliferação de um movimento para a mudança.

O movimento do acesso livre acredita ter a resposta para esta questão crítica: os líderes desse movimento não estão tão interessados em reformar o sistema de comunicação investigacional já existente, mas, sim, em transformá-lo para que possa funcionar com eficácia num ambiente tecnológico em rápida mudança.

De acordo com Borges (2006, p. 81), o movimento do acesso livre começou em 1994, quando Stevan Harnad dá início a sua proposta "subversiva" numa lista de discussão disponível na internet dedicada ao tema das revistas eletrônicas (OKERSON; O' DONNEL 1995 apud BORGES, 2006). $\mathrm{Na}$ resposta a essa proposta, esteve presente Paul Ginsparg, o criador do arquivo de Los Alamos, atualmente conhecido Arxiv, um arquivo de preprints na área da física e da alta energia, cujo sucesso permitiu todo novo horizonte na partilha da Informação Científica.

Rodrigues (2006), após a publicação da "Proposta Subversiva", assim denominada pelo seu próprio autor, Stevan Harnad, sublinha que várias iniciativas foram ocorrendo em favor do movimento do acesso livre em todo o mundo, nomeadamente: a criação da Scholarly Publishing and Academic Resources Coalition (SPARC); a Declaração de Santo Domingo; a Conferência Mundial Sobre A Ciência para o Século XX; a Declaração sobre a Ciência e o Uso do Conhecimento Científico; a Agenda para a Ciência; a Convenção de Santa Fé - a Iniciativa de Arquivos Aberto; o Lançamento da Pubmed Central.

$\mathrm{Na}$ origem do movimento de Acesso Livre estão os problemas, limitações e contradições do sistema de comunicação da ciência, em particular os relacionados com as revistas científicas. De facto, nas últimas décadas do século XX o crescimento acentuado da literatura científica, nos mais diversos ramos do saber, foi acompanhado pela "comercialização", e pela perda de controlo por parte do mundo académico, do sistema de comunicação da ciência (RODRIGUES, 2006). 
Existe uma multiplicidade de definições do que vem a ser Acesso Livre, mas o "Acesso Livre diz respeito à acessibilidade ampla e irrestrita a conteúdos disponíveis em formato digital, no sentido em que remove barreiras de preço e de permissão, tornando a literatura científica disponível com o mínimo de restrições de uso" (SUBER, 2003 apud BATISTA et al., 2007, p. 5).

Swan (2006, p. 1) descreve o movimento do acesso livre como resultado de uma longa história de comunicação acadêmica, que sempre esteve ligada às mudanças tecnológicas e econômicas. Artigos científicos e monografias têm estado implicados nas recentes mudanças, mas são talvez os desenvolvimentos recentes na disseminação de artigos científicos, que mais têm exercitado as mentes dos investigadores, livreiros e editores.

O OA não é mais do que a vontade expressa de um autor oferecer - o que já acontece com os meios tradicionais de publicação - os resultados validados da sua pesquisa a um conjunto ilimitado de pessoas (pares ou público em geral) para maximimizar o seu uso e impacto e é este, na verdade, o objetivo. Mas não é apenas o autor quem beneficia do impacto de citação também a unidade de investigação e a universidade onde está inserido são co-beneficiários do sistema (BORGES, 2006, p. 75).

Para Mueller (2006, p. 1), o movimento para o acesso livre ao conhecimento científico pode ser considerado o evento mais significativo da nossa época, no que se refere à comunicação científica, e, neste sentido, se torna um grande desafio para a comunidade acadêmica. Quanto mais sucesso obtiver o movimento, maior será o impacto sobre as mudanças provocadas no sistema tradicional. Segundo Foster (2008), o acesso livre tornou-se um assunto importante para determinados pesquisadores e uma oportunidade de exploração para universidades, no que concerne à troca de impressões acerca de novidades e mudanças na comunicação acadêmica, capacidade de pesquisa e modelos para edição.

Suber (2006 apud BAILEY, 2006) caracteriza assim o cerne do conceito do acesso livre: o acesso livre elimina as "barreiras de preço" (por exemplo, as taxas de subscrição) e as "barreiras de permissão" (tais como, os direitos de autor e as restrição de licença) à "literatura realmente livre" (ou seja, os trabalhos de investigação criados sem fins lucrativos pelos autores), tornandose disponíveis balizados por "restrições de utilização mínimas" (por exemplo, a atribuição de autor).

O Brasil vem distinguindo-se quanto às políticas de acesso à informação. Tem realizado diferentes iniciativas em favor do acesso livre. De acordo com Melo, Sampaio e Pires (2007), o Brasil, devido à dimensão do seu território e, consequentemente, às desigualdades regionais, não se desenvolve de maneira semelhante nas diversas regiões, pelo que especificamente no contexto educativo, ainda convive com diferenças na educação das classes mais abastadas, por um lado, e das classes menos favorecidas, por outro lado. Nesse seguimento, os autores supracitados destacam o impacto das diferenças regionais e do investimento na disseminação do conhecimento, defendendo que as regiões que possuem mais conhecimento podem partilhar os seus recursos informacionais com as regiões menos beneficiadas, cooperando para o desenvolvimento geral da nação.

A partir de 2005, com a elaboração do Manifesto Brasileiro de apoio ao Acesso Livre à Informação Científica, e segundo Kuramoto (2008), o Brasil vem realizando, através do IBICT, várias inciativas em favor desse movimento, entre as quais podemos mencionar: a assinatura da Declaração de Berlim (2003); a submissão, a aprovação e o desenvolvimento do Projeto de Publicações Periódicas de Acesso Livre (PCAL), na Financiadora de Estudos e Projetos (FINEP); a prospecção, a identificação, a absorção, a customização o aperfeiçoamento e a distribuição de tecnologias para o tratamento e disseminação da informação, que sustentem as ações de acesso livre a 
exemplo do Sistema Eletrônico de Editoração de Revistas (SEER); a construção de repositórios institucionais e temáticos de acesso livre; Projeto de Lei (PL) n. 1120/2007, que dispõe sobre o processo de disseminação da produção científica; a implantação da Biblioteca Digital Brasileira de Teses e Dissertações (BDTD). Para além dessas iniciativas, foram publicados, em 2006, um número especial da Revista Ciência da Informação (35:2), e, em 2008, da Revista LIINC (4:2) ambas com artigos de pesquisadores brasileiros e estrangeiros sobre o tema do acesso livre.

Salientamos também a participação brasileira na Iniciativa ALEMPLUS (2006), no Compromisso do Minho (2006) e a Cooperação Luso-brasileira (2009). Esta última foi realizada com a finalidade de aumentar a difusão do conhecimento científico em língua portuguesa nos países lusófonos e no mundo.

\section{QUESTÕES METODOLÓGICAS}

De acordo com Grawitz (1993 apud CARMO; FERREIRA, 2008), os métodos de investigação consistem num conjunto de operações que são realizadas para atingir um determinado objetivo, sendo, portanto, um corpus de princípios, que preside a toda investigação organizada, obedecendo às seguintes etapas: definição do problema; revisão da literatura; formulação da hipótese ou questão de investigação; definição da população-alvo; escolha das técnicas de recolha de dados; determinação da dimensão da amostra; seleção das técnicas de amostragem adequada; e, por fim, seleção ou desenvolvimento de um instrumento de recolha de dados.

No decorrer da pesquisa, foram utilizados, como instrumentos de recolha de dados, a entrevista e os questionários. Foi utilizada, como métodos de operacionalização, a triangulação metodológica, que consiste no uso de diferentes metodologias. Foram empregues, ao longo do estudo, ora a abordagem quantitativa, ora a abordagem qualitativa, como forma de enriquecimento na procura da precisão na investigação. Para medir a utilização de periódicos de acesso livre e de repositórios institucionais para acesso e disseminação da informação, foi utilizada a abordagem quantitativa, na qual os objetivos e os procedimentos da investigação foram rigorosamente indicados. $\mathrm{O}$ mesmo projeto foi precedido de uma revisão de literatura fundamental para elaboração dos objetivos da pesquisa, formulação da hipótese e definição das variáveis. Os objetivos desse tipo de investigação incidem em encontrar relações entre variáveis. $\mathrm{E}$ foi também empregue a abordagem qualitativa, que se caracteriza por indutiva, holística, naturalista e humanística.

Enquanto investigação descritiva, a descrição das informações foi rigorosa, resultando diretamente dos dados recolhidos, como a transcrição de entrevistas, em que foram analisadas as notas recolhidas. Os dados recolhidos respeitaram a forma segundo a qual foram registrados na tentativa de analisar e encontrar a melhor resposta para a questão de investigação. Nesse contexto, a utilização da abordagem qualitativa e da abordagem quantitativa revela diferentes aspectos da realidade empírica envolvida na pesquisa, pois o fato de utilizar diferentes métodos permite uma melhor compreensão dos fenômenos analisados.

Um dos primeiros passos, na estruturação do projeto de pesquisa, foi a elaboração do modelo de análise, que estabeleceu os parâmetros para a realização da pesquisa, determinando o que se queria investigar. Assim, este procedimento envolveu o conceito de comunicação científica que, segundo Garvey e Grifith (1979 apud LEITE; COSTA, 2006, p. 207), compreende o conjunto de todas as atividades que englobam a produção, disseminação e uso da informação desde o início do processo de criação científica, segundo o qual as ideias da pesquisa são geradas até o momento da aceitação dos resultados como parte do corpo de conhecimento científico e os componentes foram consultados e selecionados de acordo com a Plataforma Lattes/Currículos Lattes, tal como apresentamos no quadro 1. 
Quadro 1-Modelo de análise

\begin{tabular}{|c|c|c|c|}
\hline Conceitos & Dimensões & Componentes & Indicadores \\
\hline \multirow[t]{2}{*}{$\begin{array}{l}\text { Comunicação } \\
\text { científica }\end{array}$} & $\begin{array}{l}\text { Produção } \\
\text { bibliográfica }\end{array}$ & $\begin{array}{l}\text { - Artigos completos } \\
\text { publicados em periódicos } \\
\text { - Livros } \\
\text { - Capítulos de livros } \\
\text { - Textos em jornais e revistas } \\
\text { (magazine) } \\
\text { - Trabalhos publicados em anais } \\
\text { de eventos, apresentação de } \\
\text { trabalhos } \\
\text { - Tradução } \\
\text { - Prefácio, Posfácio } \\
\text { - Relatório de Pesquisa }\end{array}$ & $\mathrm{N}^{o}$ de Publicações \\
\hline & Produção Técnica & $\begin{array}{l}\text { - Software } \\
\text { - Trabalhos técnicos } \\
\text { - Cursos de curta duração } \\
\text { - Desenvolvimento de material } \\
\text { didático ou instrutivo } \\
\text { - Editoração } \\
\text { - Programas de rádio e TV }\end{array}$ & $\mathrm{N}^{\mathrm{o}}$ de Publicações \\
\hline \multirow[t]{2}{*}{ Acesso livre } & No mundo & $\begin{array}{l}\text { Ações e movimentos } \\
\text { implementados }\end{array}$ & $\begin{array}{l}\text { Efeitos e } \\
\text { consequências }\end{array}$ \\
\hline & No Brasil & Ações realizadas & $\begin{array}{l}\text { Impactos e influências } \\
\text { (gênero, idade, } \\
\text { instituição, categoria, } \\
\text { Instituição c/ } \\
\text { repositórios e } \\
\text { instituição que } \\
\text { promove o } \\
\text { autoarquivamento) }\end{array}$ \\
\hline
\end{tabular}

Fonte: Autora, 2013.

O modelo de análise, constituído a partir dos conceitos básicos utilizados no início da elaboração do projeto de pesquisa, trata da comunicação científica e do acesso livre (sem restrições) à comunicação científica. Ao longo deste trabalho, utilizamos duas dimensões para o conceito de comunicação científica: (1) produção bibliográfica, que envolve os trabalhos publicados, tais como artigos completos publicados em periódicos, livros, capítulos de livros, textos em jornais e revistas (magazine), trabalhos publicados em anais de eventos, apresentação de trabalhos, traduções, prefácios, posfácios, relatórios de pesquisa, que aqui são utilizados como componentes da dimensão bibliográfica e, por sua vez, o número de publicações foi utilizado como indicador, com a finalidade de verificar a produção bibliográfica em acesso livre; (2) produção técnica, que envolve a criação de software, trabalhos técnicos, cursos de curta duração, desenvolvimento de material didático ou instrucional, editoração, programas de rádio e TV, aqui utilizados como componentes da dimensão produção técnica, e os números das respectivas publicações, funcionaram como indicadores.

O conceito de acesso livre à comunicação científica possui duas dimensões: (1) no mundo e como componente, utilizamos as ações e movimentos implementados em prol do acesso livre à informação científica e, como 
indicador, utilizamos os efeitos e/ou consequências dessas ações sobre o acesso livre à informação científica; (2) no Brasil, como componente, usamos ações realizadas no país em favor do acesso livre à informação científica e, como indicadores, os impactos ou influências dessas ações sobre o acesso livre à informação científica, levando em consideração o gênero, a idade, a instituição onde leciona ou estuda, a categoria que ocupa na carreira de docente, instituição onde trabalha ou estuda e possui repositórios e instituição que promove $\mathrm{o}$ autoarquivamento.

Os conceitos, as dimensões, os componentes e indicadores estabelecidos no quadro1 nortearam o desenvolvimento e a estruturação do corpo da pesquisa.

\section{RESULTADOS}

A pesquisa efetuada procurou identificar os efeitos e/ou as consequências desse movimento sobre a comunidade acadêmica da área de Biblioteconomia na Região Nordeste do Brasil e, como podemos verificar, através dos indicativos apresentados, nomeadamente dos inquéritos aplicados aos professores e alunos dos cursos de Biblioteconomia da Região Nordeste do Brasil, é possível concluir o impacto do OA nas comunidades acadêmicas da área de Biblioteconomia no Nordeste do Brasil.

Verificamos que a maioria dos professores respondentes $(67,3 \%)$ informou que a universidade onde trabalha possui repositório institucional de acordo com a tabela 1.

Tabela 1 - A universidade onde trabalha possui repositório

\begin{tabular}{|l|c|c|}
\hline $\begin{array}{c}\text { A universidade onde trabalha possui } \\
\text { repositório institucional }\end{array}$ & $\begin{array}{c}\text { Frequência } \\
(\mathbf{N})\end{array}$ & $\begin{array}{c}\text { Percentual } \\
(\mathbf{\%})\end{array}$ \\
\hline Sim & 33 & $\mathbf{6 7 , 3}$ \\
\hline Não & 16 & 32,7 \\
\hline
\end{tabular}

Fonte: Autora, 2013.

A maior parte dos professores respondentes possui produção bibliográfica em OA $(74,3 \%)$. De fato, os docentes respondentes possuem um elevado número de publicações em OA, conforme a tabela 2:

Tabela 2 - Possui produção bibliográfica em OA

\begin{tabular}{|c|c|c|}
$\begin{array}{c}\text { Possui produção } \\
\text { bibliográfica em } \\
\text { AO }\end{array}$ & $\begin{array}{c}\text { Frequência } \\
\text { (N) }\end{array}$ & $\begin{array}{c}\text { Percentual } \\
\text { (\%) }\end{array}$ \\
\hline Sim & 26 & $\mathbf{7 4 , 3}$ \\
\hline Não & 9 & 25,7 \\
\hline
\end{tabular}

Fonte: Autora, 2013.

A grande maioria dos professores respondentes $(90,0 \%)$ utiliza produção bibliográfica em OA para realização de seus trabalhos acadêmicos, de acordo com a tabela 3.

Tabela 3 - Utiliza produção bibliográfica em OA

\begin{tabular}{|c|c|c|}
$\begin{array}{c}\text { Utiliza produção } \\
\text { bibliográfica em } \\
\text { AO }\end{array}$ & $\begin{array}{c}\text { Frequência } \\
\text { (N) }\end{array}$ & $\begin{array}{c}\text { Percentual } \\
\mathbf{( \% )}\end{array}$ \\
\hline Sim & 36 & $\mathbf{9 0 , 0}$ \\
\hline Não & 4 & 10,0 \\
\hline Fonte: Autora, 2013. & & \\
\hline
\end{tabular}

E como mostra a tabela seguinte, podemos constatar mais um indicador positivo do movimento OA no Brasil: uma grande parte dos professores inquiridos $(83,3 \%)$ conhece o movimento do OA, de acordo com a tabela 4 . 
Tabela 4 - Conhece o OA

\begin{tabular}{|l|c|c|}
\hline $\begin{array}{c}\text { Conhecimento do } \\
\text { AO }\end{array}$ & $\begin{array}{c}\text { Frequência } \\
(\mathbf{N})\end{array}$ & $\begin{array}{c}\text { Percentual } \\
\mathbf{( \% )}\end{array}$ \\
\hline Sim & 40 & $\mathbf{8 3 , 3}$ \\
\hline Não & 8 & 16,7 \\
\hline
\end{tabular}

Fonte: Autora, 2013.

Para comprovar esta abertura, a maioria dos inquiridos $(97,5 \%)$ concordam com o movimento do OA, como demonstra a tabela 5 .

Tabela 5 - Concorda com o OA

\begin{tabular}{|c|c|c|}
\hline \multicolumn{2}{|c|}{ Concordância com o movimento OA } \\
\hline $\begin{array}{c}\text { Concorda com o } \\
\text { Movimento do } \\
\text { OA }\end{array}$ & $\begin{array}{c}\text { Frequência } \\
\text { (N) }\end{array}$ & $\begin{array}{c}\text { Percentual } \\
\mathbf{( \% )}\end{array}$ \\
\hline Sim & 39 & $\mathbf{9 7 , 5}$ \\
\hline Não & 1 & 2,5 \\
\hline Fonte: Autora, 2013. & & \\
\hline
\end{tabular}

A realização desta pesquisa permitiu adquirir informações sobre o movimento OA no mundo e, de uma forma muito especial, no Brasil.

Como fator bastante positivo para o movimento do OA no Brasil, a maior parte das Universidades inquiridas possui Repositórios Institucionais (RI): o RI da Universidade Federal da Bahia (UFBA), Universidade Federal de Alagoas (UFAL), Universidade Federal do Rio Grande do Norte (UFRN) e Universidade Federal do Maranhão (UFMA) encontram-se instalados; o RI da Universidade Federal de Pernambuco (UFPE) está em fase de testes; o RI da Universidade Federal do Ceará (UFC) já possui um link e publicações depositadas e será lançado oficialmente no segundo semestre de 2011; só o RI da Universidade Federal da Paraíba (UFPB) ainda não foi implantado, mas $O$ Departamento de Ciência da Informação onde funciona o curso de Biblioteconomia nesta universidade possui um repositório. Todos os RI acima citados fazem parte da
Relação dos Repositórios Brasileiros que utilizam o Dspace, e o RI da UFRN e UFMA estão registrados no Directório Lusobrasileiro - repositórios e revistas de acesso aberto, todos foram implantados a partir dos recursos oriundos da FINEP. Mas, comprovadamente, pelo baixo percentual de produção bibliográfica e produção técnica de docentes e discentes respondentes depositadas em RI, não existe ainda uma política estabelecida para divulgar e incentivar o autoarquivamento (via verde) e a disponibilização da produção científica de professores e alunos nesses RI. Apesar de existir um alto percentual de utilização de RI entre os docentes respondentes, enquanto os alunos não o utilizam, mas estes, como os professores, usam periódicos eletrônicos em OA.

Apesar de a maioria das universidades da região inquirida possuir RI, ainda é significativamente baixo o número de produção bibliográfica de docentes, e principalmente de discentes, depositada nesses repositórios.

A maioria dos professores e alunos respondentes utiliza produção bibliográfica em OA nos seus mais variados tipos, sobretudo artigos publicados em periódicos eletrônicos em OA, mas só os docentes possuem um número significativo de produção bibliográfica publicada em OA.

Comprovadamente, a maioria dos docentes conhece e concorda com o movimento do OA, outro fator de impacto do movimento do OA no Brasil. Ao contrário dos discentes respondentes, cuja maioria desconhece o OA, a minoria que conhece também concorda com O movimento do AO.

Os docentes respondentes assim como os discentes possuem uma opinião formada sobre o OA, mas ainda não asseguram que "O movimento do $\mathrm{OA}$ promove o aumento de citações da produção bibliográfica de professores e pesquisadores". Apesar de inúmeros estudos comprovarem essa afirmação e de uma forma mais bem acentuada, também não afirmam que "as publicações bibliográficas em OA têm a mesma importância das 
publicações bibliográficas em revistas impressas com avaliação prévia feita pelos pares conforme o modelo tradicional".

Apesar de a maioria das universidades da região inquirida possuir RI, ainda é significativamente baixo o número de produção bibliográfica de docentes e principalmente de discente depositada nesses repositórios. Isso se justifica pelo fato de os referidos repositórios terem sido recentemente implantados e, sendo assim, reafirma-se a falta de incentivo ao autoarquivamento para promover e disponibilizar a produção bibliográfica produzida nas IES do nordeste do Brasil;

A produção técnica de docentes e discentes publicada em OA, em RI e em RI da instituição onde lecionam ou estudam é irrelevante, se comparada ao número de produção bibliográfica de docentes em $\mathrm{OA}$, em RI e em RI da instituição onde lecionam. Justifica-se isso pelo fato de a produção técnica ser relativamente baixa nas chamadas ciências sociais e, principalmente, na Ciência da Informação, além da falta de incentivo ao autoarquivamento nas Instituições de Ensino Superior (IES) do nordeste do Brasil, mas a maioria dos docentes e alunos respondentes utilizam produção técnica em $\mathrm{OA}$, principalmente de material didático e instrucional e de software;

Independentemente da instituição onde lecionam e estudam, a maioria dos professores e alunos respondentes concorda totalmente e concorda com as afirmações apresentadas sobre o $\mathrm{OA}$, com relação ao acesso, à disseminação e à visibilidade, mas existe uma dispersão entre os professores e alunos respondentes com relação às afirmações "o movimento do OA promove o aumento do número de citações de professores pesquisadores" e "as publicações bibliográficas em OA têm a mesma importância das publicações bibliográficas em revistas impressas com avaliação prévia realizada pelos pares";
A maior parte dos professores e alunos respondentes que lecionam e estudam em instituições que possuem repositórios concorda totalmente com as afirmações sobre o OA, com relação ao acesso, à disseminação e à visibilidade, mas, independentemente de a instituição onde lecionam ou estudam possuir repositórios, existe uma distribuição entre os professores e alunos respondentes com relação às afirmações "o movimento do OA promove o aumento do número de citações de professores pesquisadores" e "as publicações bibliográficas em OA têm a mesma importância das publicações bibliográficas em revistas impressas com avaliação prévia feita pelos pares";

Como verificamos, através da revisão de literatura e dos resultados dos inquéritos aplicados, podemos afirmar que a comunidade acadêmica da área de Biblioteconomia na Região Nordeste do Brasil concorda e aceita o acesso livre, sendo que já se torna visível o impacto ou a influência do movimento do acesso livre no Brasil e, especificamente, na Região Nordeste.

Contudo, dever-se continuar a investir na divulgação do movimento em prol do acesso livre e a implementar programas e projetos, de forma a ampliar e estimular a utilização do autoarquivamento (via verde) e a criação de periódicos de acesso livre (via dourada). Esse impulso não deverá ser proporcionado só através do governo brasileiro, só através do IBCT, mas também através do envolvimento direto das próprias comunidades acadêmicas com os seus pares, nas suas instituições, para que o acesso livre se torne de fato uma alternativa para a disseminação do conhecimento científico e para que o Brasil, especificamente a Região Nordeste, tenha a possibilidade de aumentar a visibilidade da sua produção científica no país e no mundo. 


\title{
OPEN ACCESS AND ACADEMIC COMMUNITIES OF THE BIBLIOTHECONOMY'S AREA IN THE NORTHEASTERN REGION OF BRAZIL
}

\begin{abstract}
Verify the influence of the Open Access $(O A)$ on the academic communities of the bibliotheconomy in the Federal Universities of the Northeast of Brazil. Its general aim is to identify and discuss the influence of the $\mathrm{O} A$ movement. The adopted methodology consists of the combination of the qualitative and quantitative approaches; questionnaires and interviews were used as data collection instruments. The interview was applied to the senior technologist of the Brazilian Institute of Information on Science and Technology (IBICT) - Instituto Brasileiro de Informação em Ciência e Tecnologia) aiming at obtaining information on the $O A$ movement in Brazil. The questionnaires were applied to teachers and students of the Bibliotheconomy courses, aiming to verify the effects and consequences of the $O A$ movement in those communities The survey outcomes conduct to several positive indicators of the $\mathrm{O} A$ movement influence in those academic communities, among which we can include: the existence of institutional repositories in Northeastern Federal Universities, a high institutional reposittories, a high percentage of use of publications in $O A$, as well as the production of bibliographic publications with $O A$; the knowledge and concordance with $O A$ movement show the impact of this movement on the academic communities in the Northeastern Region of Brazil.
\end{abstract}

Keywords

Open Access. Open Access - influence. Open Access - Northeastern Region of Brazil.

Artigo recebido em 25/11/2013 e aceito para publicação em 11/03/2014

\section{REFERÊNCIAS}

BAILEY, Charles Jr. What is open acess? In: JACOBS, Neil. Open Access: key strateic, tecnical and economic aspecs. England: Chandos, 2006. p. 13-26.

BAPTISTA, A. et al. Comunicação científica: o papel da Open Archives Initiative no contexto do acesso livre. Enc. Bibli: R. Eletr.

Bibliotecon. Ci. Inf., Florianópolis, n. esp. $1^{\circ}$ sem., p. 5-17, 2007. Disponível em:

$<$ http://repositorium.sdum.uminho.pt/bitstre am/1822/8727/1/2007EncontrosBibli.pdf > .

Acesso em: 11 nov. 2010, 14:24.

BINOTTO, Maria Angélica. Democratizar o acesso aos conhecimentos científicos: como, onde e porquê. Revista Digital. Buenos Aires, ano 11, n. 105, fev. 2007.

Disponível em:

$<$ http://www.efdeportes.com/efd105/democr atizar-o-acesso-aos-conhecimentos-

cientificos.htm>. Acesso em: 9 dez. 2009, $14: 30$
BORGES, Maria Manuel. A esfera: comunicação acadêmica e novos media. Coimbra, 2006. 1 CD-ROM.

CAFÉ, Lígia; LAGE, Márcia Basílio. Autoarquivamento: uma opção inovadora para a produção científica. DataGramaZero. Rio de Janeiro, v. 3, n. 3, jun. 2002. Disponível em: <http://www.dgz.org.br/jun02/Art_04.htm>. Acesso em: 12 dez. 2009.

CARMO, Hermano; FERREIRA, Manuela M. Metodologia da investigação: guia para auto-aprendizagem. 2. ed. Lisboa: Universidade Aberta, 2008. 375p. ISBN 119169-97.

FERREIRA, Sueli Mara S.P.; MUNIZ JÚNIOR, José de Souza. O Movimento do livre acesso e a democratização de conteúdos científicos: um projeto de editoração eletrônica de revistas de ciências da comunicação [2005]. Disponível em: <http://dici.ibict.br/archive/00000568/01/ar tigo1.PDF>. Acesso em: 10 nov. 2010, 14:08.

FOSTER, Connie. Foreword: revisiting new in four years? Serials Rewiew. v. 34, n. 1, p. 11 12, mar. 2008. Disponível em: 
$<$ http://journals.ohiolink.edu/ejc/article.cgi?is $\mathrm{sn}=00987913 \&$ \&issue $=\mathrm{v} 34 \mathrm{i} 0001 \&$ article $=11 \_\mathrm{fr}$ oaanify $>$. Acesso em: 14 maio 2009.

JACOBS, Neil. Open Access: key strategic, technical and economic aspects. England: Chandos, 2006. 243p. ISBN 184334 203-0.

KURAMOTO, Hélio. Acesso livre à informação científica: novos desafios. Liinc em Revista. Rio de Janeiro, v. 4, n. 2, 2008. Disponível em: <http://www.ibict.br/liinc > Acesso em: 12 set. 2009.

LEITE, Fernado C. L.; COSTA, Suely. Repositórios institucionais como ferramentas de gestão do conhecimento científico no ambiente acadêmico. Perspect. ciênc. inf., Belo Horizonte, v. 11, n. 2, p. 206-219, mai./ago. 2006. Disponível em: <http://www.scielo.br/pdf/\%0D/pci/v11n2 /v11n2a05.pdf > . Acesso em: 15 mar. 2011, 18:38.

MELO, L. B; SAMPAIO, M. I. C; PIRES, C. A questão do acesso aberto em Portugal e no Brasil. In: SEMINÁRIO NACIONAL DE BIBLIOTECAS UNIVERSITÁRIAS, 15, 2008, São Paulo. Anais eletrônicos... São Paulo. UNICAMP, 2008. Disponível em: <http://www.sbu.unicamp.br/snbu2008/anai s/site/pdfs/2796.pdf $>$. Acesso em: 12 nov. 2009.

MORAES, Rosana P. T. de. O "livre acesso" e os "arquivos abertos" na comunicação cientifica. Niterói: [s.n.], 2006. 59p.

Disponível em:

<http://dici.ibict.br/archive/00001150/01/M onografia_Rosana_Portugal.pdf $>$. Acesso em: 25 out. $2010,16: 21$.

MORENO, Fernanda P.; ARELLANO, Miguel A. M. Publicações científicas em arquivos de acesso aberto. Arquivística.net. Rio de Janeiro, v. 1, n. 1, jan./jun. 2005. Disponível em: <http://www.periodicos.ufrgs.br/admin/sobr elinks/arquivos/Publicacao_acesso_aberto.pdf >. Acesso em: 12 nov. 2009.
MUELLER, Suzana P. M. A comunicação científica e o movimento de acesso livre ao conhecimento. Ciência da Informação. Brasília, v. 35, n. 2, p. 27-38, maio-ago. 2006. Disponível em: <http://www.scielo.br/pdf/ci/v35n2/a04v35 n2.pdf $>$. Acesso em: 30 out. 2006.

RODRIGUES, Eloy. Acesso livre: utopia ou realidades. In: ENCONTRO NACIONAL DE BIBLIOTECAS JURÍDICAS, 1, 2004, Lisboa, Direito e informação: actas...Coimbra: Coimbra, 2006. ISSN 08703116. p. 29-40. Disponível em: $<$ http://repositorium.sdum.uminho.pt/handle /1822/4942>. Acesso em: 12 dez. 2009.

SENA, Nathália K. Open archives: o caminho alternativo para comunicação científica.

Ciência da Informação. Brasília, v. 29, n. 30, p. 71-78, set. - dez. 2006. Disponível em: <http://www.scielo.br/scielo.php?script $=$ sci_ arttext\&pid $=$ S0100-19652000000300007> Acesso em: 30 out. 2010.

SOARES, Gláucio A. D. Portal de periódicos CAPES: dados e pensamentos. RBPG Revista Brasileira de Pós-graduação, Brasília, n. 1, p. 10-25, jul. 2004. Disponível em:

<http://www2.capes.gov.br/rbpg/images/sto ries/downloads/RBPG/Vol.1_1_jul2004_/10 _25_o_portal_de_periodicos.pdf $>$. Acesso em: 28 out. $2010,15: 34$.

SWAN, Alma. Overview of scholarly comunicação. In: JACOBS, Neil. Open Access: key strategic, technical and economic aspects. England: Chandos, 2006. cap. 1. 